\title{
Modified Twin Block for a Class II Division 1 Hypodontia
}

\section{Case}

Jain $\mathbf{U}^{1 *}$, Bharti $\mathbf{C}^{1}$, Chhajed $\mathbf{R}^{1}$ and Bharti $\mathbf{H V}^{2}$ ${ }^{1}$ Department of Orthodontics \& Dentofacial Orthopedics, Peoples College of Dental Sciences \& Research Centre, India

${ }^{2}$ Bharti's Multispeciality Dental Clinic, India

*Corresponding author: Upendra Jain, Department of Orthodontics \& Dentofacial Orthopedics, Peoples

College of Dental Sciences \& Research Centre, Bhanpur, Bhopal (M.P), India

Received: March 09, 2017; Accepted: April 26, 2017; Published: May 11, 2017

\begin{abstract}
This article describes the management of a case with severe Class II skeletal discrepancy treated with growth modification therapy. As the patient was in cervical vertebral maturation (CVM) stage 3 , it was planned to make use of the remaining growth for correction of skeletal discrepancy and so treatment was initiated with a modified twin block with acrylic teeth incorporated in the anterior upper and lower appliance so as to motivate the patient. This promoted the growth of the mandible, restrained maxilla in antero-posterior direction followed by alignment and leveling of the dentition with fixed appliance.
\end{abstract}

Keywords: Twin block; Hypodontia; Cervical vertebral maturation

\section{Introduction}

Class II malocclusion is one the most commonly observed malocclusion in about one third of the population. This malocclusion is characterized by maxillary protrusion, mandibular retrusion or combination of both however, mandibular skeletal retrusion being the most consistent finding [1]. Correction of Class II malocclusion may be approached by growth modification, dental camouflage, and surgical orthodontics [2].

For treating growing class II patients, functional appliance is often applied in the stage of late mixed dentition or early permanent dentition to reduce excessive over jet by stimulating the growth of the mandible [3].

The twin block appliance, originally developed by Clark is widely used functional appliance worn most of the time for the management of class II malocclusion. The appliance allowed nearly full range of mandibular movements, easy acclimatization, reasonable speech and good patient compliance providing high patient acceptability with rapid results [4].

The following case report documents a case of 14 year old girl treated by a phase I growth modification therapy using twin block appliance with acrylic teeth incorporated into it followed by a phase II pre-adjusted Edgewise appliance therapy to settle the occlusion and correct the remaining dental discrepancy.

\section{Case Presentation}

A 14-year-old female came to Department of Orthodontics \& Dento-facial orthopedics, People's College of Dental Science \& Research Centre, Bhopal with the chief complaint of forwardly placed teeth and unpleasant appearance of the face (Figure 1).

The patient had history of trauma in the upper front tooth region for which endodontic treatment was performed Figure 2A.

Extra-oral examination:

(a) Frontal View

i) Facial symmetry: Apparently symmetrical
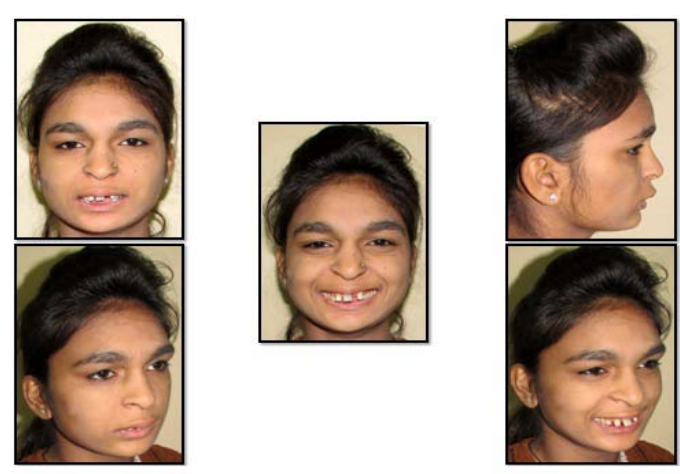

Figure 1: Pre-treatment extra-oral photographs.
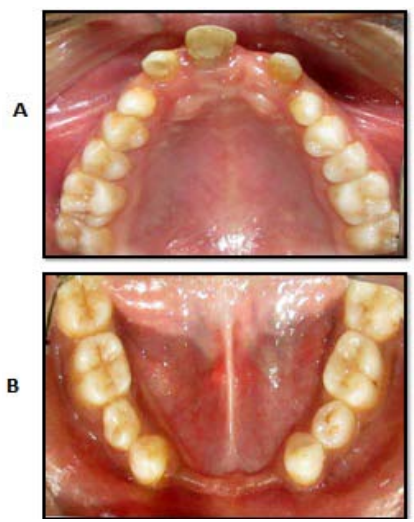

Figure 2A \& B: Pre-treatment intra-oral photographs.

ii) Facial thirds: 53:58:43 proportional

iii) Incisor exposure: $3 \mathrm{~mm}$ at rest

(b) Profile view

i) Facial profile: Convex

ii) Lip protrusion: protruded with lower lip trap

iii) Chin: receding 


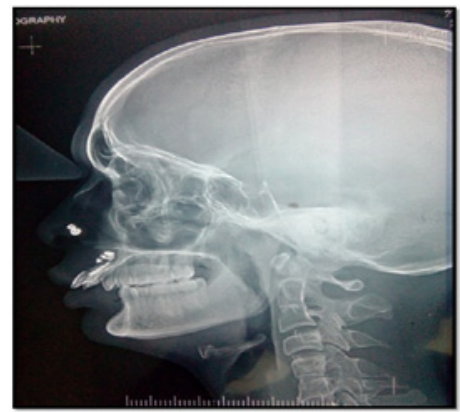

Figure 3: Pre-treatment extra-oral photographs. Post extraction of 11.

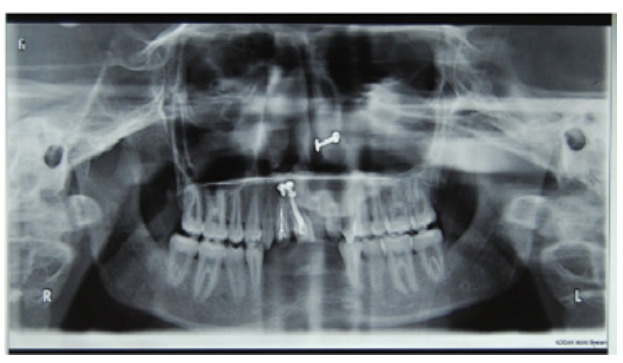

Figure 4: Pre-treatment intra-oral photographs. Post extraction of 11.

Table 1: Visual treatment objective (VTO): positive.

\begin{tabular}{|c|c|c|}
\hline Cephalometric Variable & Pre-Treatment & Post-Functional \\
\hline SNA & 75 & 74 \\
\hline SNB & 71 & 73 \\
\hline ANB & $4 \mathrm{~mm}$ & $1 \mathrm{~mm}$ \\
\hline A to B on FH & $7 \mathrm{~mm}$ & $6 \mathrm{~mm}$ \\
\hline N perp. to Pt. A & $-13 \mathrm{~mm}$ & $-7 \mathrm{~mm}$ \\
\hline N perp. to Pog. & $-22 \mathrm{~mm}$ & $-7 \mathrm{~mm}$ \\
\hline BJORK SUM & 382 & 385 \\
\hline SN-GoGn & 25 & 22 \\
\hline Y-Axis & 62 & 58 \\
\hline
\end{tabular}

Intra-oral examination:
(a) Teeth present: 17-12, 22-27, 47-44, 34-37
(b) Missing teeth: $31,32,33,41,42,43$
(c) Molar relationship: Class I on both sides
(d) Canine relationship:---
(e) Overbite: --
(f) Midline: --

On intra-oral examination, patient had congenitally missing lower anteriors (Figure 2B) from canine to canine, with history of accidental avulsion of left maxillary central incisor (21) along with non-vital right maxillary central incisor, root canal treatment was done for 11, but due to poor prognosis it was extracted before commencing any orthodontic treatment (Figure 3,4 ) (Table 1).

\section{Diagnosis}

Angle's class Imalocclusion on a skeletal class II normal divergent
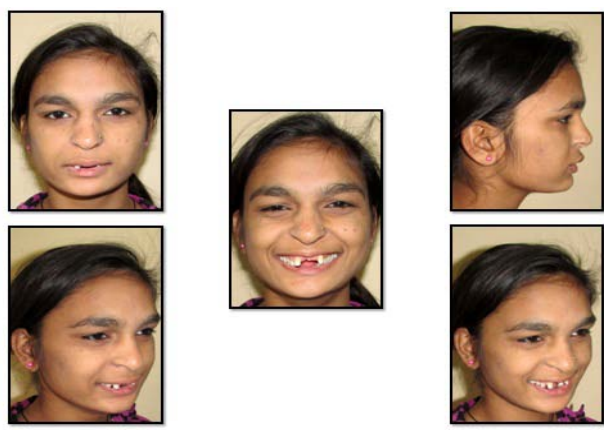

Figure 5: Articulated models of the patient with bite, wire bending 7 acrylic teeth.

jaw bases.

\section{Treatment goals}

1) To correct severe Class II skeletal base relationship.

2) To maintain Class I molar relationship bilaterally.

3) To improve the soft tissue profile.

4) To align and level upper and lower arches.

5) To achieve normal overjet and overbite.

6) To create a consonant smile and an esthetic smile.

\section{Treatment plan}

Considering the skeletal and dental discrepancy two treatment approaches were thought appropriate:

(i) Functional appliance to correct the underlying skeletal discrepancy.

(ii) Fixed appliance for final detailing.

The two phase treatment plan was deemed more appropriate for this case and the patient's parent consent for this plan understanding the cost of treatment was obtained.

\section{Phase I treatment}

Functional appliance therapy with modified twin block.

\section{Appliance selection}

Twin block was the first choice as it provided the comfort of function, advancement of mandible, and restriction of maxillary growth.

\section{Design and construction}

A vertical height of $5 \mathrm{~mm}$ in the premolar region and advancement of $5 \mathrm{~mm}$ was planned. Since, the advancement of mandible resulted in a cross bite, an expansion screw (jack screw) was incorporated for transverse maxillary expansion which had to be activated every week.

Delta clasp was fabricated on $16,26,34,44$. Acrylic teeth were incorporated on acrylicbase plate in both maxillary and mandibular anterior tooth region i.e. two central incisor in maxillary arch and four mandibular incisors in mandibular arch. In maxillary arch, jack screw was incorporated in the acrylic base plate so as to achieve expansion in constricted maxillary arch (Figure 5). 


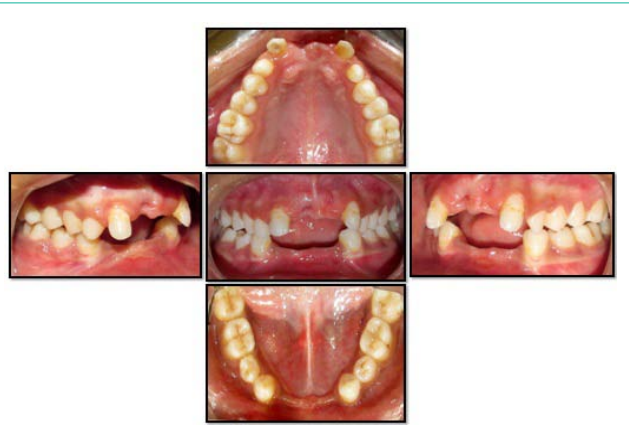

Figure 6: Pre-treatment intraoral photographs.

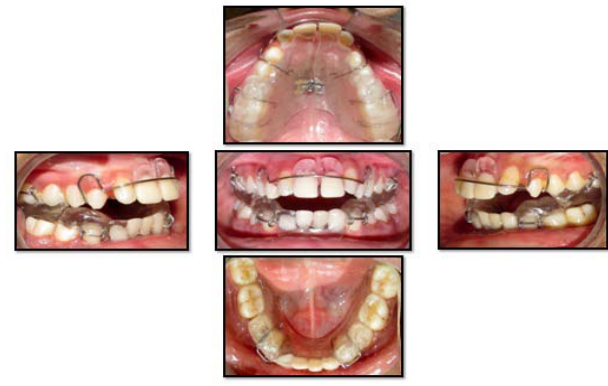

Figure 7: Post twin block therapy treatment extra-oral photographs.

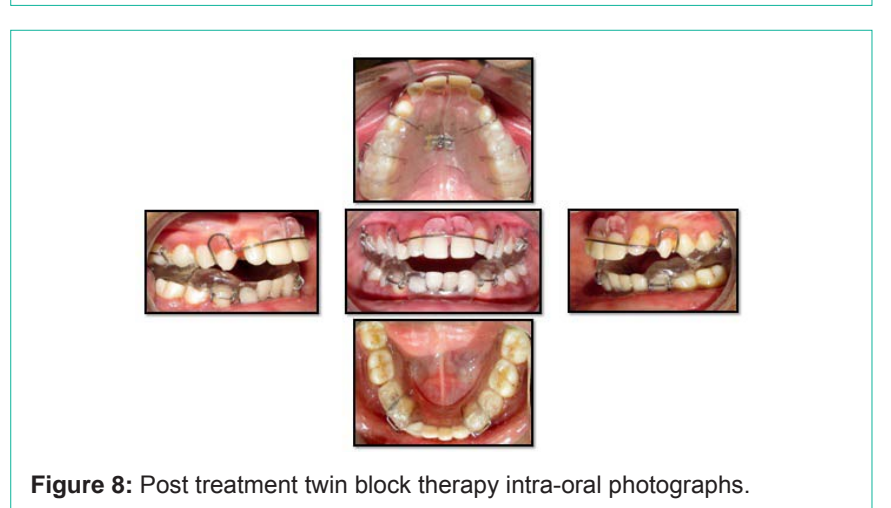

\section{Appliance use and appointment scheduling}

Basic appliance (Figure 6) care instruction was explained to the patient. The first two appointments were spaced at a week interval. The recall appointments were scheduled every month for any adjustments needed and selective grinding of the acrylic to redirect the erupting teeth for leveling the excessive curve of speed.

\section{Follow up}

Selective grinding of the acrylic was performed to allow permanent teeth eruption during phase I treatment. The upper arch was expanded to correct buccal cross bite.

After 11 months of phase I treatment, the patient showed an improved facial profile and bilateral super class I molar (Figure 7,8).

\section{Phase II treatment: fixed appliance}

The treatment aims of the early phase treatment was to redirect and stimulate the growth of lower jaw so as to improve the profile, while the aim of phase II treatment was to achieve good interdigitation.

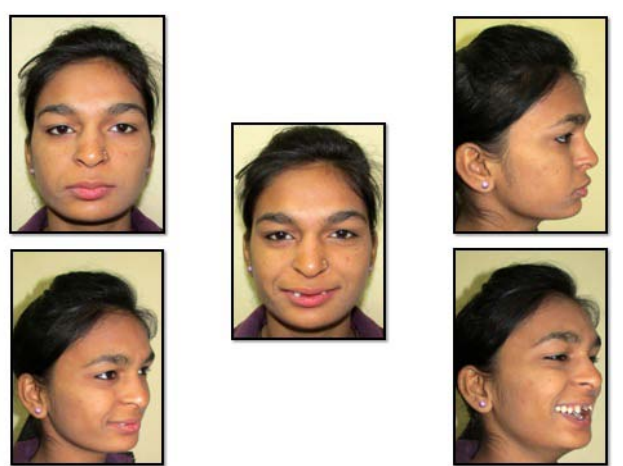

Figure 9: Intra-oral photographs. Stage 1: Alignment with $0.012 \mathrm{Ni}$ Ti.

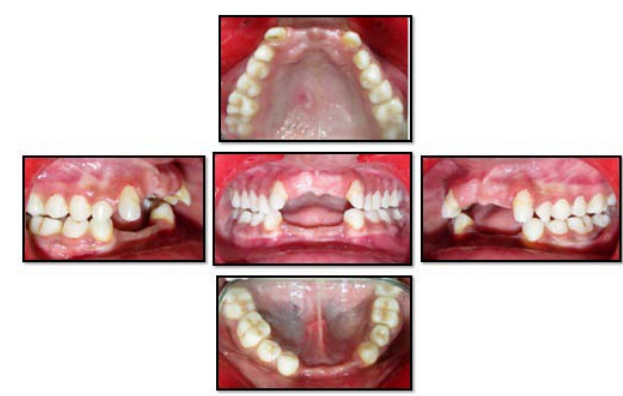

Figure 10: Mid-treatment extra-oral photographs. Stage 2: levelling with 19x25 HANT.

Table 2: Wrap around retainer with reverse bite plane was planned for full time use for 1 year and thereafter nighttime use for 6 months.

\begin{tabular}{|l|l|c|}
\hline Treatment & Archwires & $\begin{array}{l}\text { Duration } \\
\text { (Months) }\end{array}$ \\
\hline $\begin{array}{l}\text { Correction of skeletal } \\
\text { dysplasia }\end{array}$ & $\begin{array}{l}\text { Modified Twin Block with } \\
\text { expansion screw }\end{array}$ & 8 months \\
\hline $\begin{array}{l}\text { Alignment of upper and } \\
\text { lower arches }\end{array}$ & $\begin{array}{l}\text { 1) } .012,0.016 \text { NiTi wire } \\
\text { 2) } 19 x 25 \text { HANT }\end{array}$ & \multirow{2}{*}{11 months } \\
\hline Incisor intrusion & .018 AJ with RCS & \\
\hline Finishing and detailing & .014 AJ Wilcock & \\
\hline Retention & U/L Wrap around retainers & \\
\hline
\end{tabular}

The case was strapped up from first molar to first molar using 0.22 inch slot; metal brackets; Pre adjusted Edgewise Appliance with MBT versatile $^{+\mathrm{TM}}$ (Ortho-organizer) prescription and a sequence of 0.012 inch NiTi (Figure 9), 0.016 inch NiTi, 19x25 HANT (Figure 10) wires were used for aligning followed by $19 \times 25$ stainless steel wire (Figure 11). Final finishing was done with 0.014 inch Australian Stainless steel wire with short class II elastics. The fixed appliance phase took 10 months to finish (Table 2).

\section{Discussion}

As there have been no cases of hypodontia (Figure 1) reported which have been treated with orthodontic functional appliance followed by fixed appliance, this case report is different from this perspective. This case is an example of mutilated case so treatment was performed in two phases in which modified twin block was placed in first phase with acrylic teeth incorporated into the edentulous space followed by fixed orthodontic appliance.

Clark's twin block is a functional appliance, which effectively 


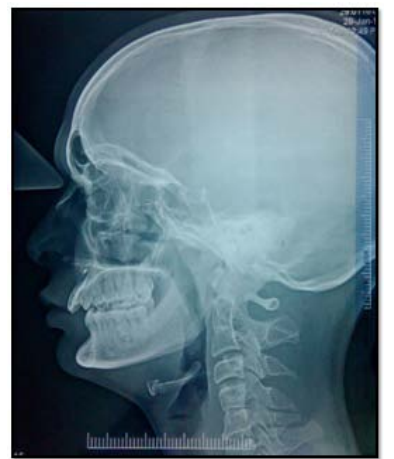

Figure 11: Mid-treatment intraoral photographs. Stage 2: levelling with $0.019 \times 0.025$ SS with removable partial denture.

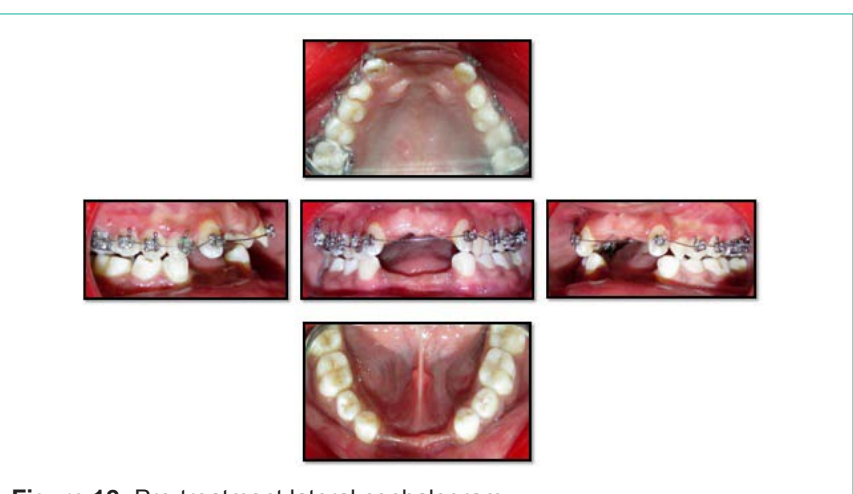

Figure 12: Pre-treatment lateral cephalogram.
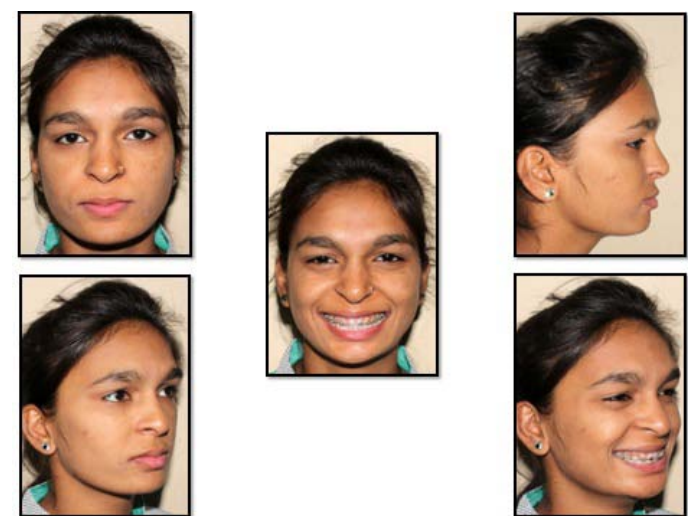

Figure 13: Pre-treatment orthopantomogram.

modify occlusal inclined plane which induce favorably directed occlusal force by causing a mandibular displacement, allowing masticatory function $[4,5]$. Being a suitable appliance for mixed and permanent dentition [6] along with being esthetic, easy to repair, and robust, many studies have shown that this appliance produce significant combination of skeletal as well as dentoalveolar changes responsible for class II malocclusion correction [7-9].

Twin block was given to patient as the patient was in growth phase having CVM III (Figure 12) stage. Twin block was modified with incorporation of acrylic teeth (Figure 5) into the upper and lower edentulous space, along with jackscrew in the upper plate for correction of constricted maxillary arch. The incorporated acrylic
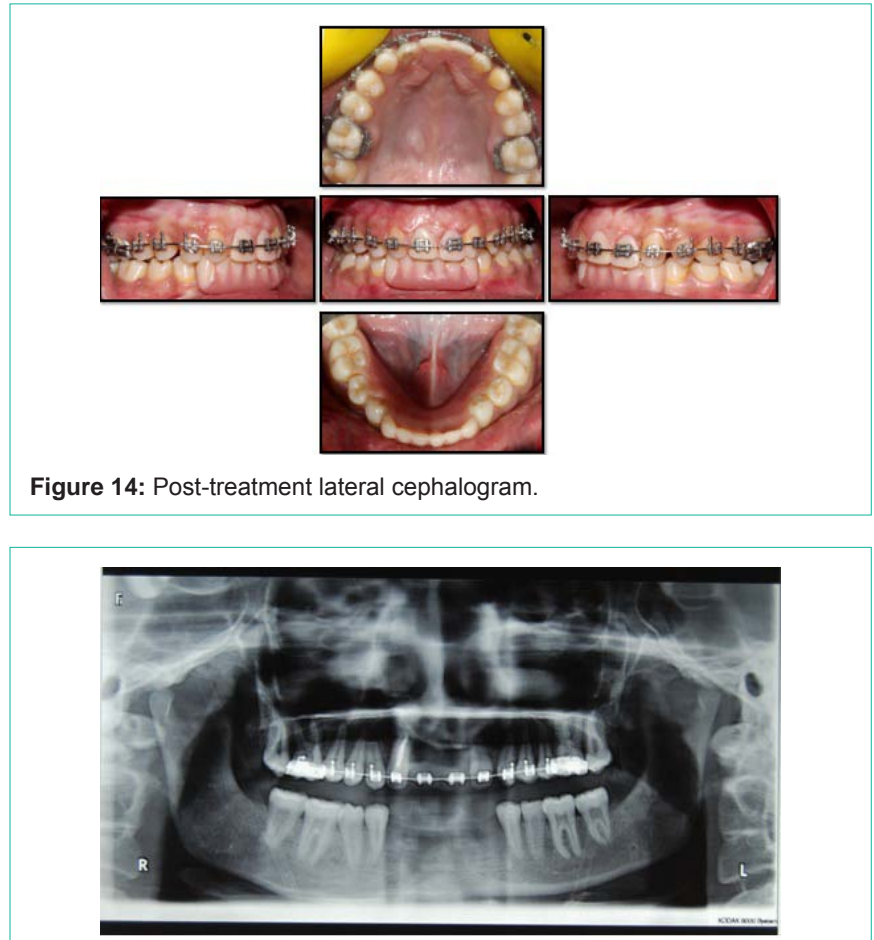

Figure 15: Post-treatment orthopantomogram.

teeth into the appliance will have motivating effect on the patient psychology making her more motivated towards the treatment and increasing patient compliance.

In this case, the treatment objectives were achieved largely due to good compliance by the patient provided the disguising of the anterior edentulous area by acrylic teeth providing positive influence on the patient for orthodontic treatment (Figure 6). The patient has history of trauma in the upper front tooth region 2 years back. When the patient reported to the department her 21 was lost in the accident while 11 was maintained in the oral cavity but it was discolored (Figure 2A,B).

On OPG (Figure 13) root canal treatment of the 11 had been performed, root canal filling material extruded from the apex of the tooth and tooth showed poor prognosis, due to which tooth was extracted. Here, on comparison of pre-treatment and post-treatment lateral cephalogram (Figure 3,14,15) showed SNA remained relatively unchanged ( 75 degrees to 74 degrees), and SNB increased by 2 degrees. ANB angle reduced by 3 degrees improving the antero-posterior relationship of the maxilla and mandible improved. Maxillary forward movement was restrained, and the mandibular apical base moved forward in relation to cranial base, which proved that twin block produced head gear effect, like all the functional appliances.

\section{Long-term prognosis}

The prognosis for stability is good as the patient's growth pattern is favorable. Good buccal interdigitation and incisal contact also helped to stabilize the occlusal stability, as well as retainers.

\section{Conclusion}

Twin block functional appliances brought profile improvement 
in the face but also addition of acrylic teeth motivated the patient towards the treatment.

\section{References}

1. Jena AK, Duggal R, Prakash H. Skeletal and dento-alveolar effects of twin block and bionator appliances in the treatment of Class II malocclusion: a comparative study. Am J Orthod Dentofacial Orthop. 2006;130: 594-602.

2. Proffit WR, Fields HW Jr, Sarver DM. Contemporary Orthodontics. 4th ed. Missouri: Elsevier; 2007.

3. Graber TM, Rakosi T, Petrovic A. Dentofcail Orthopedics with Functional Appliances. St. Louis, Mo: Mosby;1997; 346-352.

4. Clark WJ. The twin block traction technique. Eur J Orthod. 1982; 4: 129-138

5. Clark WJ. The twin block technique. A functional orthopedic appliance system. Am J Orthod Dentofacial Orthop. 1988; 93: 1-18.
6. Al-Anezi SA. Class II malocclusion treatment using combined Twin block and fixed orthodontic appliances-A case report. Saudi Dent J. 2011; 23: 43-51.

7. Trenouth MJ. A comparison of Twin Block, Andresen and removable appliances in the treatment of Class II Division 1 malocclusion. Funct Orthod. 1992; 9: 26-31.

8. Trenouth MJ. Cephalometric evaluation of the Twin-block appliance in the treatment of Class II Division 1 malocclusion with matched normative growth data. Am J Orthod Dentofacial Orthop. 2000; 117: 54-59.

9. Singh GD, Hodge MR. Bimaxillary morphometry of ppatients with class II division 1 malocclusion treated with twin block appliances. Angle Orthod. 2002; 72: 402-409.
Austin J Dent - Volume 4 Issue 4 - 2017

ISSN : 2381-9189 | www.austinpublishing group.com

Jain et al. @ All rights are reserved
Citation: Jain U, Bharti C, Chhajed R and Bharti HV. Modified Twin Block for a Class II Division 1 Hypodontia Case. Austin J Dent. 2017; 4(4): 1076 